\title{
Intelligent Systems for Functional Improvement of Buildings
}

\author{
Osama Omar
}

\begin{abstract}
The design and development of sustainable environments can be considered as a shared duty, especially in the current state of climate change and ecological awareness. The role of a few major stakeholders, such as architects, in ensuring a reliable and suitable environment design is even more critical, as the construction industry currently consumes half the energy sources globally. Therefore, improving the way in which our environment is designed challenges certain cultural systems, such as education for future architects and engineers, which currently demonstrates evident limitations. The digital transformation is increasingly affecting all aspects of life. This research focuses on new development strategies for improving functionality in existing buildings through enhancing students' ability to think critically in the face of environmental challenges, using digital processing tools to achieve a sustainable building. The research approaches are both quantitative and qualitative, with an emphasis on problem-solving (ARCH463: Intelligent Buildings). Four steps have been followed: literature review; assessment and analysis; guidelines creation; and tests and simulations. One of the results of this research is to create development strategies for the functional improvement of an existing building through promoting course and interest in the students of an elective course (ARCH463: Intelligent Buildings) in the second level of architecture in the Faculty of Architecture, Beirut Arab University, Beirut, Lebanon. Another outcome will be the practical effectiveness of new technology devices in sustainable intelligent building in the Arab countries.
\end{abstract}

Index Terms-Intelligent buildings, environmental challenge, architectural education, sustainable teaching, digital tools.

\section{INTRODUCTION}

The definition of sustainable design was established according to the World Commission on Environment and Development in 1987, then known as the Brundtland Report. It declared that a sustainable development responds to current needs without compromising future generations' ability to meet their own necessities (World Commission on Environment and Development [1]).

The European Intelligent Building Group has also defined 'intelligent building' as a building that creates an environment that maximizes the productivity of the occupants of the building, while allowing efficient resource management with minimum lifetime costs for equipment and facilities (Wong et al. [2]; Wigginton et al. [3]).

In recent years, environmental and energy issues have drawn a good deal of attention among the numerous

Manuscript received October 29, 2019; revised January 7, 2020.

Osama Mohamed Omar is with Faculty of Architecture, Design and Built Environment, Beirut Arab University, Beirut, Lebanon (e-mail: o.omar@bau.edu.lb,ossamamoh.omar@gmail.com). problems faced by the modern generation. Not only does indiscriminate energy use have a direct impact on the quality of life of individuals, but it is also connected to serious environmental effects such as the depletion of energy resources, global warming, climate change, carbon emissions, acid rain and waste retention. While the rise in energy usage indicates the industry's economic growth in emerging nations, it also contributes to some concerns with regard to energy sources. Consequently, the need to find alternative energy sources is more crucial than ever, as the population grows and the demand for energy grows, while taking into consideration the fact that renewable resource such as fossil fuels are becoming more limited. In all developing countries, buildings are among the biggest energy consumers (Pérez-Lombard et al. [4]; Junnila et al. [5]).

For example, in Iran, the building industry is responsible for $36 \%$ of its total energy consumption. This makes it essential to study the energy consumption and environmental impact of buildings during their life cycles. One of the most effective ways of overcoming the energy consumption problem is to improve energy efficiency in the upcoming generation of buildings, reducing energy consumption, operational costs and $\mathrm{CO}_{2}$ emissions. This growing need for a green and sustainable design has led to the development of a new concept, known as intelligent buildings (IBs), which demands a steady process of equilibrium between all three environmental, social and economic aspects (Alwaer and Clements-Croome [6]). Not only do IBs attempt to provide their residents and occupants with flexibility and comfort while preserving economic efficiency, but they also address user safety, as well as achieving greater environmental performance standards (Wong et al. [2]).

In this regard, the design team's challenge is to choose the most suitable alternative among a variety of existing systems and solutions based on the customers' needs, so that the optimal configurations that meet both developers' and end users' expectations are fully implemented by optimum selection and integration of the present technologies (EIBG [7]).

\section{A. Architecture Education Pedagogy}

"The concept of education is one which only suggests criteria by which various activities and processes can be judged to see if they can be classified 'educational'. Thus, giving a lecture may be educational, but it might not be if it does not satisfy the criteria; a student design project may be educational but also might not be" (Parsons [8]).

"We conclude, in short, that architecture education is really about fostering the learning habits needed for the discovery, integration, application, and sharing of knowledge 
over a lifetime." (Boyer and Mitgang [9]).

It is thought that the conception of generative design systems and reasoning systems has resulted in several design theories, methods and models that help to offer more than just images, data or software; problem analysis models could provide methods to reveal a problem and demonstrate an approach that can lead to a possible successful solution. These generative methods have created design techniques that can efficiently convey an extensive code of design understanding, including procedural understanding of design and reasoning (Ibrahim [10]).

Skills in problem-solving and design-oriented thinking are often recognized as a main product of the architectural studio pedagogy. Such competencies are obtained via courses in architectural design and elective courses such as ARCH463: Intelligent Buildings, where learners are prompted to produce conceptual responses to a design problem (De Gaulmyn and Dupre [11]).

Various authors have discussed the need to learn - and the need to gradually shift from learning - the content of design to develop design skills in different contexts. The term "competence" refers to the extensive ability to act effectively and successfully, according to Horváth [12]. The primary objective of creating competence is to allow potential projects to function effectively in geographically dislocated cooperative design settings, depending on the design's globalization, production, servicing and distribution.

Competency allows the resolution of problems, not only in known situations but also even in unforeseen situations. From the forerunning exploratory research by Horváth [12], which included studying the related literature, experimenting with early education courses and consulting with educational experts, the understanding is that competence is a complex whole. Competence is a combination of capacities that complement each other in the context of design problem-solving. If just one capacity is lacking or considerably weaker than the others, we cannot speak of fully functional design competence. This explains why design competencies can be tackled through several aspects and divided into different elementary competencies (Horváth [12]).

By developing and conducting our recent global European product realization course, we examined opportunities to implement and demonstrate holistic design competence. According to Horváth [12], holistic design competence is a mixture of five abilities: capabilities, attitude, knowledge, skills and experience (Fig. 1). These five abilities are strongly linked, both epistemologically and methodologically (Horváth [12]).

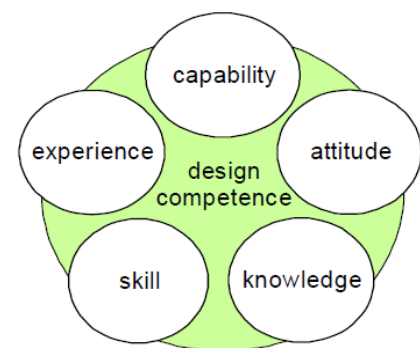

Fig. 1. Interacting constituents of design competence. Reference: Horváth [12].
All fields of life are increasingly affected by digital transformation. Students today need a broad range of collaborative skills and need to work in interdisciplinary teams and distant workspaces, while simultaneously using future-oriented digital tools. It is the responsibility of academic education to provide technical and social skills, triggering the courage and curiosity required for this lifelong learning (Vogt et al. [13]).

In architecture, computer simulations have a relatively brief background. Computer modelling is generally categorized alongside computational and applied mathematics, even though the development of its visualization techniques is inseparable from several key architecture features. Architects were involved in the development of computer-assisted representation methods even early on. Horst Rittel, a former design science lecturer at the Hoschschule School fur Gestaltung in Ulm, Germany, more than 20 years ago, referred to computer-aided simulation as one of the most significant fields in which architects interact with computers. Thanks to the fast growth of software and equipment, sophisticated numerical simulations have become a new practice in science and research, and particularly in architecture and design. Now that it is established as an omnipresent cultural technology, it is changing our interactions with the world even more. Therefore, simulations are a fundamental concept in which the repeated demands for trans-disciplinary action are expressed. This is accurate not only for the arts but also, and perhaps even more so, for an architectural, technological and scientific dialogue.

In this context, it becomes apparent that the debate of these fundamental ideas extends beyond the traditional discursive borders of architectural discourse, and is more and more marked by a thorough dialogue of the theory and philosophy of technology and scientific history. Alongside the 3D simulation technologies applied in the professional field, these have also been applied in the architecture sector, especially since the early 1990s. Design studios began using computer-modelling programs to perform 2D graphics, 3D modelling, image rendering, case simulations and interactive animations. It has become obvious that architectural education has been greatly affected by these types of software. Design studios worldwide have seen a profound change in their strategic design teaching techniques and even their furnishing methods. Students have become familiar with computer modelling programs since the 1990s, using them in their architectural design courses (Omar and Youssef [14]).

\section{B. The Main Questions}

How Encourage students to build sustainable strategies for improving the functionality of existing buildings in the face of environmental challenges? Define the gap between teaching sustainable principles in architecture education and the best practice of this in the construction industry?

\section{The Aim}

The aim is to prove that encouraging students to embed sustainable principles and strategies for functional improvement in their design concepts in the early stages of 
courses in architecture education will ensure the best practice of sustainable architecture in future.

\section{The Methodology}

The methodology used both quantitative and qualitative approaches, with a focus on problem-solving through course ARCH463: Intelligent Buildings. It followed four steps:

1) Literature review: theoretical, sustainable principles; relationship between intelligent buildings and sustainable features through lectures.

2) Evaluation and analysis: the sustainable performance of a design, while comparing various design projects and various versions of these design projects.

3) As a result of the previous steps, create guidelines for the best efficient sustainable solutions in order to improve design projects.

4) Test and simulate these guidelines through $3 \mathrm{D}$ physical modelling; present and discuss the ecological footprint of the project on the environment.

\section{E. The Outcome}

1) Build critical thinking ability in students for the development of strategies for the functional improvement of an existing building.

2) Enhance the practical effectiveness of new technology devices in sustainable intelligent building through providing technical and social skills, triggering courage and curiosity in the students.

\section{FACTORS IN EVALUATING INTELLIGENT BUILDINGS}

Based on previous research and studies, theoretical data shows that the definition and concept of the term "Intelligent Building" is still vague. It is often used in ways that are not always consistent, as shown in Omar's [15] research. In his research, Omar addressed multiple definitions and meanings assigned to this word. In fact, the reason why the term "intelligent building" is not agreed upon is because each definition is based on the competence of the subject using it. Nevertheless, one prevalent commonality still exists between all definitions: the primary objective of intelligent buildings is to decrease power consumption and the quantity of $\mathrm{CO} 2$ generated in the building industry. In this regard, Fig. 2 shows the new approaches towards the selection criteria for intelligent building in the 21 st century.

Fig. 2 illustrates the fundamental level or key elements of the definition of smart buildings from the architectural standpoint: building management systems (BMS), building automation systems (BAS), sensors, smart materials, intelligent skin or interactive façades, based upon the eight Quality Environmental Module (QEM) elements suggested by architects Albert T.P. So and Professor Wong in 1999. The selection of these requirements and conceptions will promote the project team's key objective and goal of accomplishing the most effective handling of energy usage by rationally using existing resources and by devising methods to improve power usage, while at the same time retaining a high standard of living.

The secondary definition level is split into two or more sections, expanding the architectural methods in order to facilitate the main goal of optimizing the power usage at these secondary stages, as illustrated in Fig. 3. The second level of intelligent building evaluation criteria elements comprises: interactive façades, intelligent skins, BAS, BMS, environmental sensors, interactive sensors, interactive materials, extensive properties, indoor environmental controls, environmental techniques, solar cells, wind turbines, geothermal water and all the criteria mentioned before.

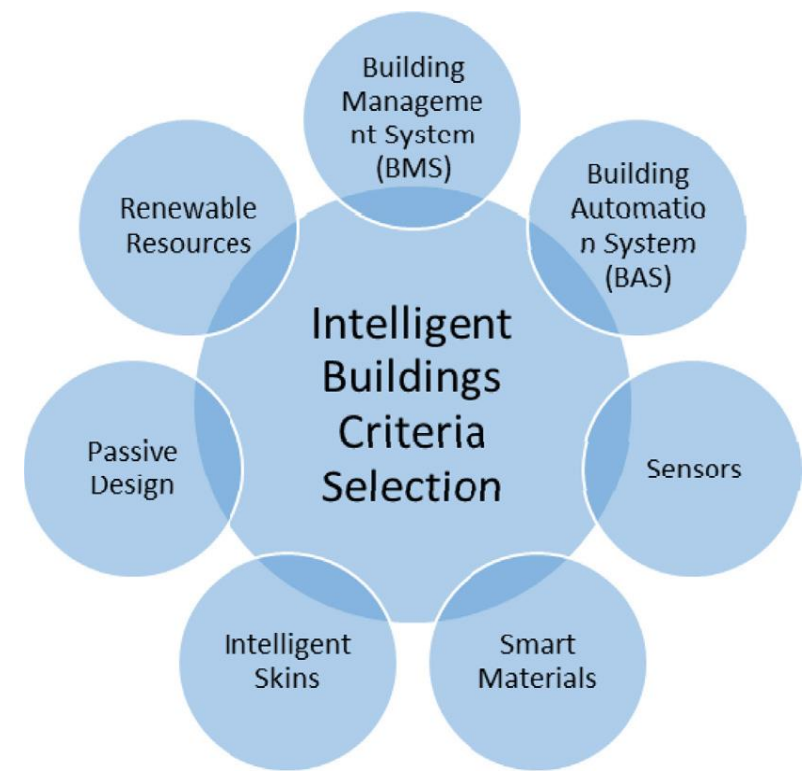

Fig. 2. Main factors in intelligent building selection criteria. Reference: Omar [15].

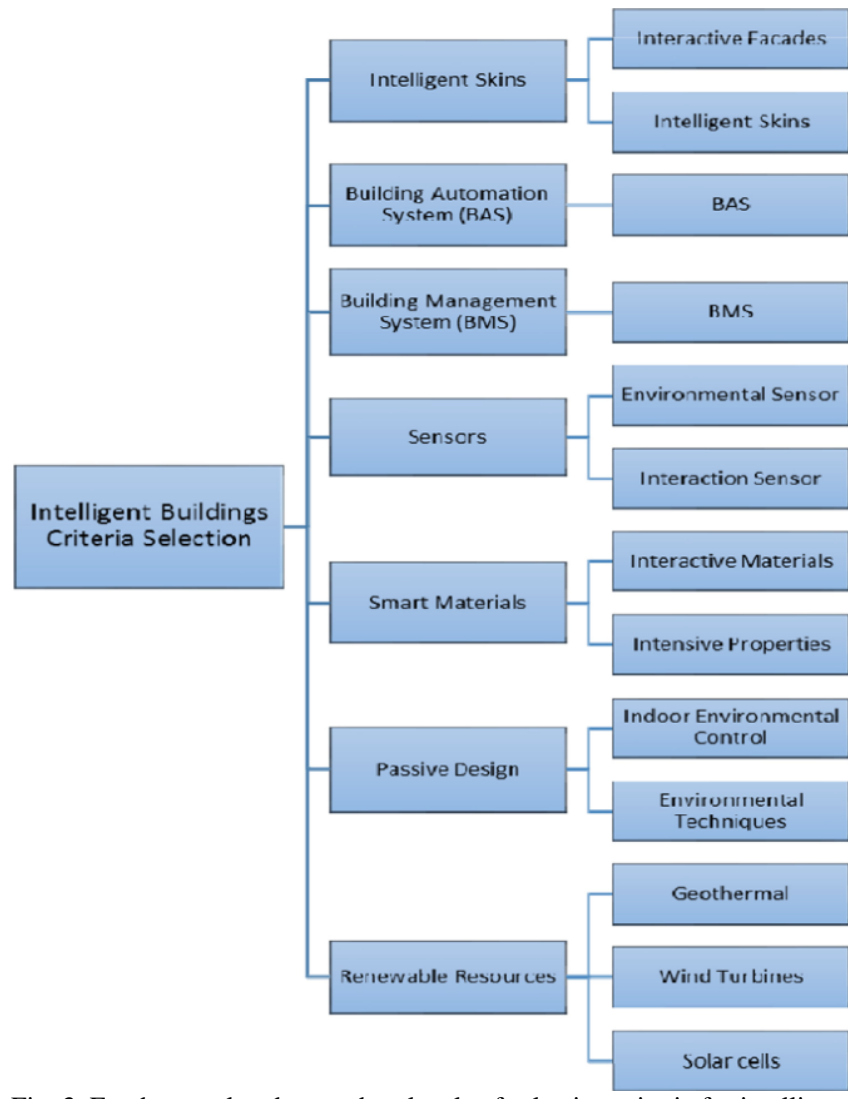

Fig. 3. Fundamental and secondary levels of selection criteria for intelligent buildings. Reference: Omar [15].

A key level containing 64 parameters concludes the third level of assessment selection criteria. This level guarantees that the base level and secondary level work consistently to 
achieve the main objective of intelligent building design, which is lowering energy usage while generating clean power and minimizing CO2 outputs (Omar [15]; Azari et al. [16]). Furthermore, the parameters shown in Fig. 3 should support achieving the objective of intelligent buildings to decrease the usage of fossil fuels and to transfer to clean, renewable energy, both of which will reflect on the functional performance of buildings.

\section{ExPERIMENTAL METhod OF PROJECT-BASEd LEARNING}

According to the Intelligent Buildings course description: "The course provides the student with advanced knowledge of intelligent buildings. The course is to create an environment that allows organizations to achieve their business objectives and maximize the effectiveness of its occupants, while allowing efficient management of resources with a minimum lifetime cost, and recognizing that intelligent buildings are responsive to human needs. At the end of this course students should know recent updates of technical innovations linked to intelligent buildings."

In this context, it is worth noting that the Intelligent Buildings course is located among the fourth year courses in the contract sheet of the architecture programme. It is targeted to support students with advanced technologies in their design projects through both a theoretical element, including a literature review about the latest technologies that could add value to their design project, and practical experience, through the application of a case study, which will be discussed later in this paper. Further, this course should reflect on other courses on the same level horizontally, such as the design studio course and execution course, and vertically in the upper level of the course, demonstrated in the knowledge of each student and in their oral skills, supporting them in their projects.

Students should also upgrade their levels of knowledge and understanding, intellectual skills, and professional and practical skills, through several intended learning outcomes, as follows:

\section{1) Knowledge and understanding}

1) Define the cultural, social and intellectual histories, theories and technologies that influence the design of buildings, and the influence of history and theory on the spatial, social and technological aspects of architecture.

2) Recall the principles associated with designing optimum visual, thermal and acoustic environments and systems for environmental comfort realized within the relevant precepts of sustainable design.

3) Learn to critically assess the balance between high and low technology.

\section{2) Intellectual skills}

1) Respond to change within the external and internal aspects of intelligent building environments.

\section{3) Professional and practical}

1) Develop appropriate effective written and oral communication skills relevant to intelligent buildings.

Different types of exercise and assignments in the course, from individual to group work, and from classwork to homework, increase the level of critical thinking from a beginner's level to intermediate and high levels of critical thinking, bearing in mind the link between horizontal and vertical courses in the same level and the upper level.

\section{A. Experimental Case Study}

The experiment was the final assignment in the course, after several levels of exercise. In this assignment, students were asked to build teams of five to six students. Each group had to present one intelligent building from around the world, ensuring that it had at least five intelligent features, analyse it through a PowerPoint presentation and try to simulate the intelligent features in the building through a $3 \mathrm{D}$ physical model, in such a way as to understand how the features work integrated within the design of the building.

The targets of this assignment were to enhance the ability of students in terms of thinking in a creative way - or, in other words, outside the box - and to increase their skills through building a 3D physical model, organizing the work, working together and applying the features in their design projects at a different level of architectural education.

\section{B. Students' Work}

- Phase One (Posters)

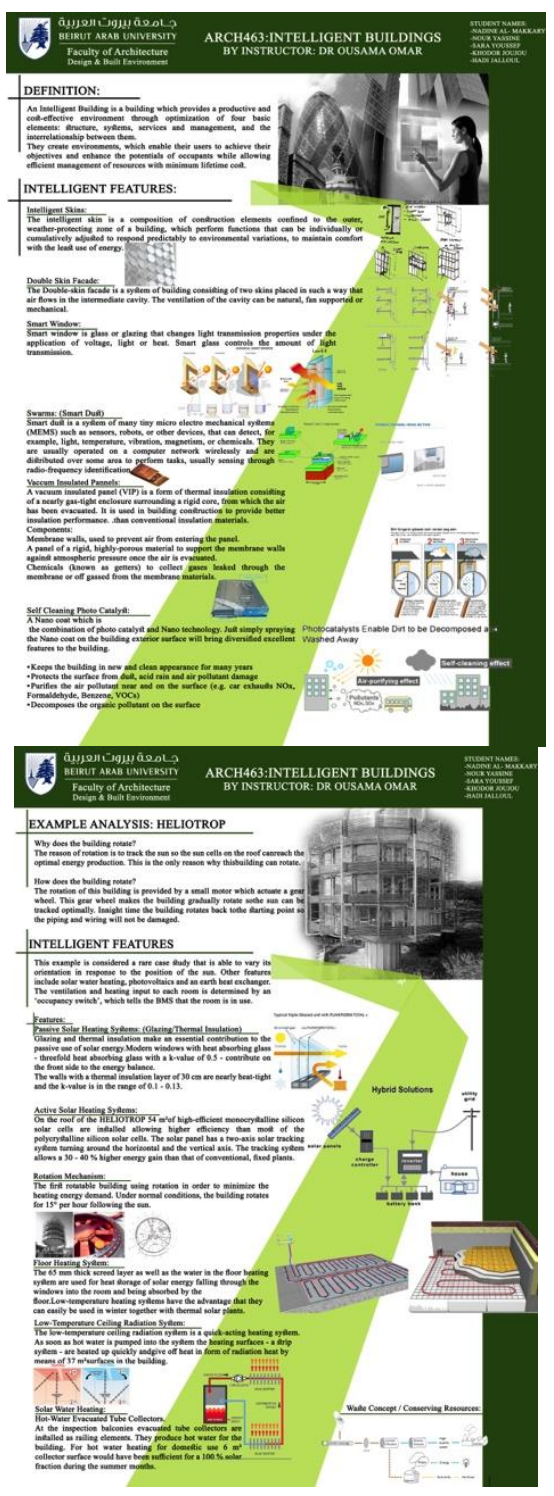




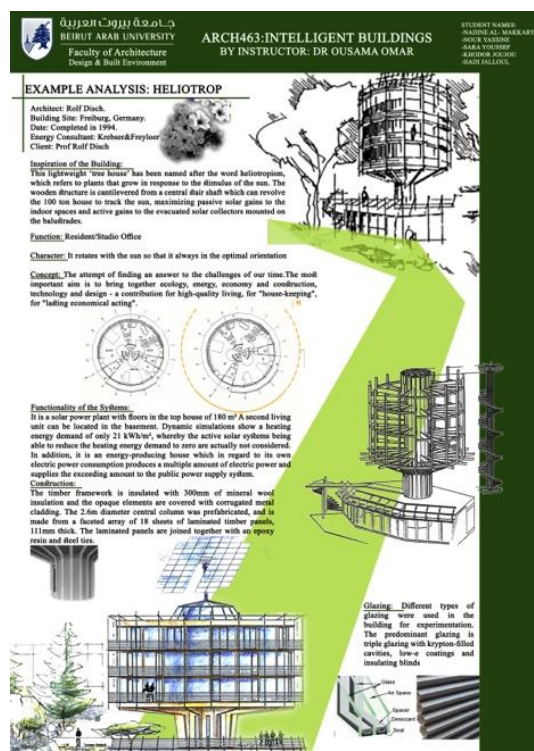

Fig. 4. An example of group work (posters). Reference: Author.

- Phase Two (3D Physical Models)

\section{AutgMATED LIGHTNING}
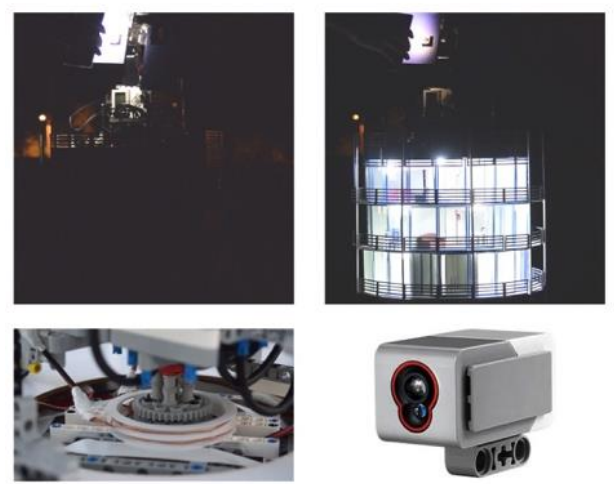

Cog CREATED AND 30 PRINTED GY GROUP

A cLLIR SENSGR WAS ADDED TO THE SILAR PANEL, WHICH CAN ALSO WORK AS A LIGHT SENSIR, DETECTING WHEN SUNLIGHT IS PRESEN DR NOT. THE SENSDR GIVES THE READINGS TD THE BRAIN, THEN THE BRAIN SENDS AN IRDER FOR THE LIGHTS TO FUNCTION IR NOT, DEPENDING IN WEATHER THERE IS STILL LIGHT OR THERE ISN'T. A SPECIAL WIRING CONNECTION WAS MADE IN IRDER TO CONNECT THE WIRES ON THE ROTATING PANEL TO THE STABLE BASE.

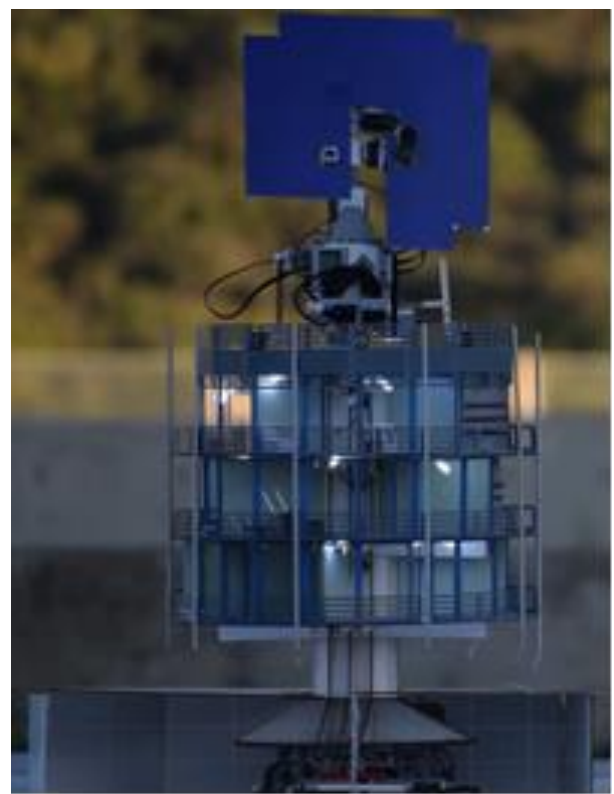

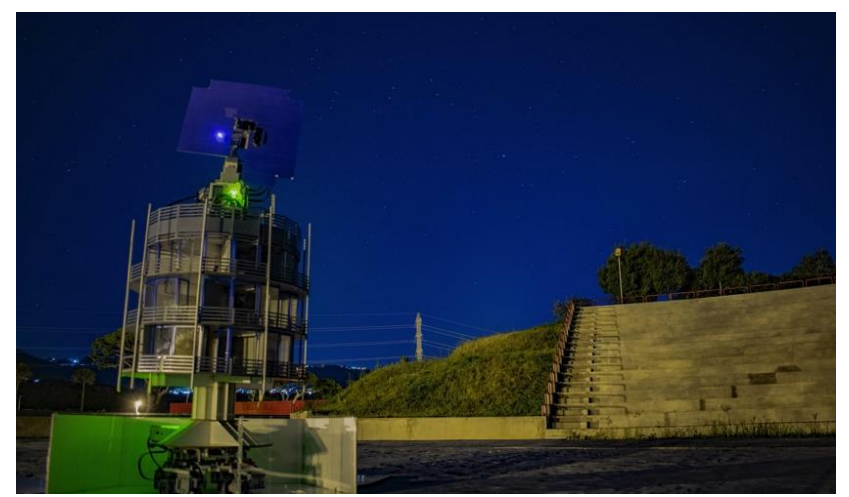

Fig. 5. An example of group work (3D physical model). Reference: Author

- Phase Three (Intelligent Features)

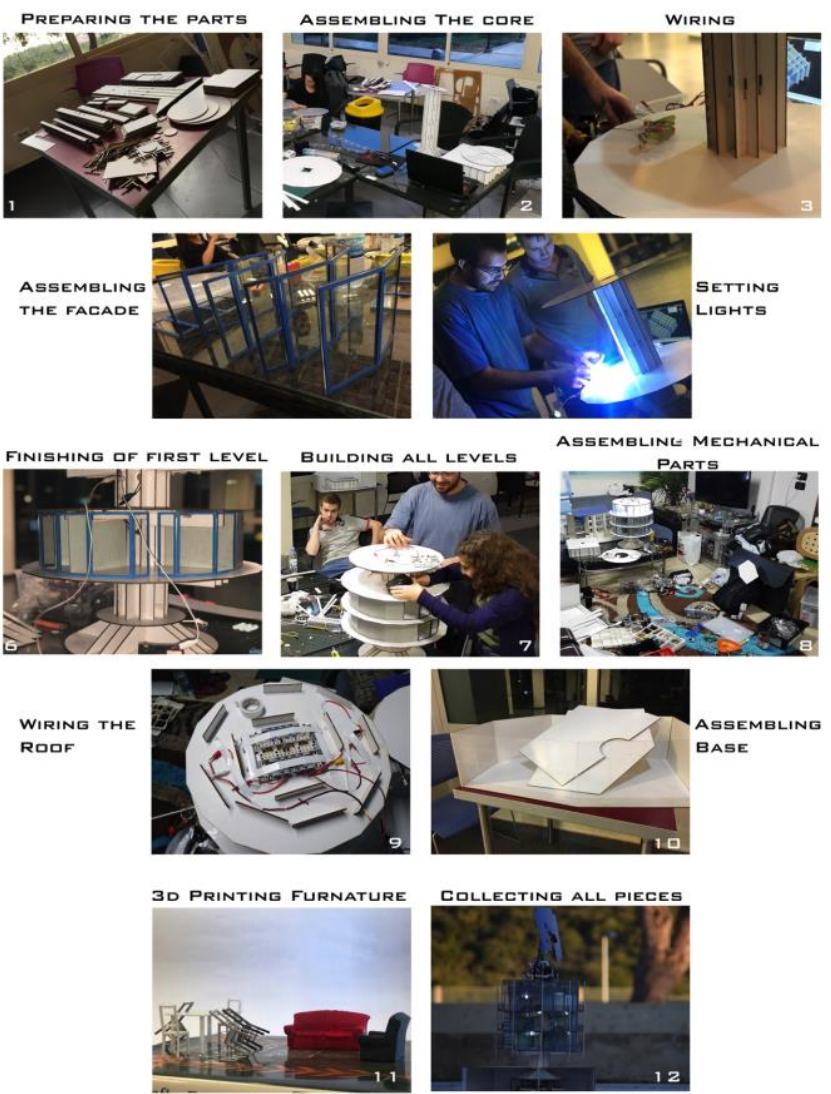

Fig. 6. Different steps to build the 3D physical model (group work). Reference: Author.

There were three stages of evaluation for student work, as can be seen above: (a) posters, as shown in Fig. 4, which evaluated the theoretical and background knowledge; in this stage student choose one building that have most of intelligent and passive features and technics to correlated it with intelligent and passive strategies that learned from theoretical part. Then they represent their criticism through posters, which include information about buildings and its location, architect, drawing, Intelligent and passive features inside this building as shown in Fig 4(b) evaluation via a practical experiment, through building physical models with all the intelligent features mentioned in their posters as shown in Figs 5, 6; and (c) an oral presentation for each group to discuss their understanding and knowledge of everything demonstrated through the posters and physical model, in order to stimulate a critical discussion about the 
principles of intelligent building that should be found inside the buildings. Further, through the oral presentations, students demonstrated the idea of adding different strategies in their design projects to reflect functional performance improvement, such as:

1) Passive architecture techniques play a major role in decreasing the cooling and heating load in the building, which founded from studying several buildings that shown passive features and technics for example like Shading system above the windows to decrease the heat transfer through direct daylight. Also, like double skin that found in several building that decrease the cooling and heating load inside the building.

2) Inserting building management systems and building automation systems in building construction will result in the huge benefit of being able to control and operate different systems in the buildings.

3) Adding sensors to adapt to different weather and smart materials will complete the whole image of reaching the target of building.

4) The transfer from fossil fuels to renewable resources should occur in many steps over years and not just in one step.

5) The target will be reached if all these parameters are added to the building together, and not by adding just one. As discussed with the students, students showed a relationship between the theoretical part as intelligent, passive features and technics and the applied of these features inside the buildings through their practical experiment which reflect on the method of teaching that enhance the students skills and the level of professionalism of their output work.

\section{CONCLUSIONS}

The aim of this research was to prove that encouraging students to embed sustainable principles in their design concepts in the early stages of courses in architecture education will ensure the best practice of sustainable architecture in the future.

In conclusion, one of the most important outcomes of this course was enhancing lifelong learning (sustainable teaching) through providing technical and social skills, triggering courage and curiosity in students. As a result, students' individual work was not convincing, whereas success was met during group work.

From an educator's point of view, the experiment showed that encouraging students and enthusing their curiosity through social interactive discussion during the course will enhance their skills and ability to create more and more sustainable solutions in their design concepts. In fact, most students who took this course showed great skills in the next academic year in their architecture design project, which was a reflection of what they learned in ARCH463: Intelligent Buildings.

Finally, it's an experimental way of teaching to teach students learning process of intelligent systems for functional improvement of buildings and discussing with students how to start grasp different (sustainable, intelligent, passive, etc. ) strategies in their design projects.

\section{CONFLICT OF INTEREST}

The authors declare no conflict of interest.

\section{ACKNOWLEDGMENT}

I want to thank all the students who took this course ARCH 463: Intelligent Buildings - with me, with a special thank you to the students who took this course in the autumn of the academic year 2017-2018: I appreciate all that you did with me during this course. I also want to thank a special group in this class, whose work is represented in this research: Hadi Jalloul, Khodor Joujou, Nadine El Makarky, Nour Yassine and Sara Youssef.

\section{REFERENCES}

[1] World Commission on Environment and Development, Our Common Future, Oxford: Oxford University Press, 1987.

[2] J. K. Wong, H. Li, and S. W. Wang, "Intelligent building research: A review,"Automation in Construction, vol. 14, p. 143e59, 2005.

[3] M. Wigginton and J. Harris, Intelligent Skin, Oxford (UK): Architectural Press, 2002.

[4] L. Pérez-Lombard, J. Ortiz, and C. Pout, "A review on buildings energy consumption information," Energy and Buildings, vol. 40, p. 394e8, 2008.

[5] S. Junnila, A. Horvath, and A. A. Guggemos, "Life-cycle assessment of office buildings in Europe and the United States," Journal of Infrastructure Systems, vol. 12, p. 10e7, 2006.

[6] H. Alwaer and D. J. Clements-Croome, "Key performance indicators (KPIs) and priority setting in using the multiattribute approach for assessing sustainable intelligent buildings," Building and Environment, vol. 45, p. 799e807, 2010.

[7] EIBG. (2001). European Intelligent Building Group. [Online]. Available: www.eibg.net.

[8] M. J. Parsons, How We Understand Art: A Cognitive Developmental Account of Aesthetic Experience, New York, NY, USA: Cambridge University Press, 1987

[9] E. Boyer and Mitgang, Building Community: A New Future for Architcture Education and Practice: A Special Report, San Frawnsisco: Jossey-Bass, 1996.

[10] M. S. Ibrahim, "Digital tools devising pedagogical approaches: Exploring the potential of rule-based design in students' competences development," International Journal of Parallel Emergent and Distributed Systems, vol. 32, 2017.

[11] C. Gaulmyn and K. Dupre, "Teaching sustainable design in architecture education: Critical reviw of easy approach for sustainable and environmental design frontiers of architectural research," Frontiers of Architectural Research, vol. 8, no. 2, pp. 238-260, 2019.

[12] I. Horváth, "Design competence development in an academic virtual enterprise," in Proc. IDETC/CIE 2006, ASME 2006 International Design Engineering Technical Conferences and Computers and Information in Engineering Conference, 2006.

[13] P. Vogt, U. Lesch, and N. Friese, "Implementing digital methods into project-based engineering courses," The Challenges of the Digital Transormation in Education, 2019.

[14] O. Omar and R. E.-M. M. Youssef, "Impact of 3D simulation modeling on architectural design education," presented at the 1st International Conference Rethinking Architectural Education, 2016.

[15] O. Omar, "Intelligent building, definitions, factors and evaluation criteria of selection," Alexandria Engineering Journal, vol. 57, pp. 2903-2910, 2018.

[16] K. T. Azari, E. Asadian, and A. V. Ardebili, "Evaluation of multicriteria selection factors of intelligent buildings," 2nd International Congress of Technology, Management and Social Sciences-16.

Copyright (C) 2020 by the authors. This is an open access article distributed under the Creative Commons Attribution License which permits unrestricted use, distribution, and reproduction in any medium, provided the original work is properly cited (CC BY 4.0). 


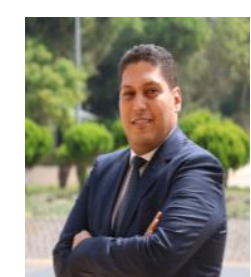

Osama Omar is an associate professor of architecture, who was born in Alexandria, Egypt (10/03/1981). He achieved his $\mathrm{PhD}$ degree in "nanoarchitecture and global warming" in (2012) from Alexandria University, Faculty of Engineering, Alexandria, Egypt. Also, His master degree "advanced daylighting technology for sustainable architectural design" (2009) from the same place. In addition, he finished his bachelor degree of architecture (2004) from Alexandria University, Faculty of Engineering, Alexandria, Egypt.

$\mathrm{He}$ is working as associate professor of architecture in Faculty of Architecture-Design and Built Environment, Beirut Arab University, Beirut, Lebanon. He is concerned for environment protection using innovative of
Nanotechnology and simple architectural solutions to limit the global warming effects. He Published several researche papers and books:

- Intelligent building, definitions, factors and evaluation criteria of selection. (Beirut, Lebanon: Alexandria Engineering Journal, 2018).

- Optimization of daylight utilization in energy saving application on the library in faculty of architecture, design and built environment, Beirut Arab University (Beirut, Lebanon: Alexandria Engineering Journal, 2018).

- Towards eco-neighborhoods, solutions for sustainable development, construction and energy saving technologies (Beirut, Lebanon: Journal of Architecture and Urbanism, 2018).

He had several research interest in nanomaterial's in building construction, indoor environmental controls, teaching architecture engineering education zero carbon and zero energy design. 